ORIGINAL ARTICLE

\title{
Post Operative Advantages of Early Enteral Feeding Over Traditional Feeding After Colostoimy Closure in Pediatric Patients
}

\author{
Atiqur Rahman', Nazrul Islam ${ }^{2}$, Shahin Reza ${ }^{3}$, Shah Alam Talukder ${ }^{4}$, Kabirul Islam $^{5}$
}

\begin{abstract}
:
The traditional practice of postoperative starvation after abdominal surgery recently has been challenged. Early enteral feeding has been shown by various clinical trials as having benefits in reduction of postoperative ileus and Hospital stay. Application of this concept to pediatric colonic surgery has not been reported. So comparing postoperative experience between early and traditional enteral feeding after colostomy closure to show the postoperative advantages of the former over the later. It is a prospective comparative study at Dhaka Medical College Hospital during July 2005 to September 2006 in 25 (age, body weight, colostomy site, operation time and follow-up duration matched) patients of colostomy closure divided in two Groups: Gr.I $(n=11)$ and Gr. II $(n=14)$ patients under went traditional enteral feeding and early enteral feeding in postoperative period respectively. Unpaired ' $t$ ' tests was used for statistical analysis. Postoperative hospital stay and postoperative complication such as vomiting, diarrhea, wound disruption were assessed. Lower gastrointestinal (G.I) bleeding, Urinary tract infection (UTI), Upper respiratory tract infection (URTI) and unspecified fever more than 48 hours were used as parameters of the study. For study Group II (Early Enteral Feeding Patients) postoperative hospital stay and postoperative complication such as vomiting, diarrhea, wound disruption. lower G.I. bleeding, UTI, URTI and unspecified fever more than 48 hours were significantly lesser than the control Group I (Traditional Enteral Feeding Patients). Parents were also found to be more satisfied with early enteral feeding in postoperative period. Through this post operative comparative study, early enteral feeding patients were found to be more advantageous than the traditional feeding patients undergoing colostomy closure.
\end{abstract}

1. Registrar, Department of Surgery, Holy Family Red Crescent Medical College Hospital, Dhaka.

2. Medical Officer, Department of Pediatric Surgery, Bangabandhu Sheikh Mujib Medical University, Dhaka.

3. Medical officer, Upazilla Health Complex, Nawabgonj, Dhaka.

4. Professor of Pediatric Surgery, Mymensingh Medical College, Mymensingh.

5. Consultant, Department of Pediatric Surgery, Square Hospital, Dhaka

\section{Introduction:}

The traditional practice of postoperative starvation after abdominal surgery recently has been challenged. Early enteral feeding has been shown by various clinical trials as having benefits in reduction of postoperative ileus and Hospital stay'. From clinical studies it suggests that initiating feeding early is advantageous in post operative patients. Postoperative dysmotility predominantly affects the stomach and Colon with the small 
bowel recovering normal function 4-8 hours after laparotomy. Feeding within 24 hours after laparotomy is tolerated and the feed is absorbed ${ }^{2}$.

Children and infants are always eager to take food orally after operation. As there were history of two operations previously incase of Anorectal Malformation or Hirschsprung's disease, the nutritional status of patients are usually not satisfactory. So early oral feeding improved the nutritional status of patients which helped them to healing the wound properly. Early feeding also had reduced the post operative complications.

When children ware admitted in a hospital, parents or their relatives had to stay with them. So extra staying in hospital hampers the normal life style of parents. More over staying in hospital increases the hospital acquired infections- such as URTI (Upper Respiratory Tract Infection) and Diarrhoea which were present more in lately oral feed patients. Early feeding helps the patients to reduce post operative hospital stay and nosocomial infections.

\section{Materials and method:}

It was a prospective study conducted at Paediatric Surgery Department of Dhaka Medical College during July 2005 to September 2006.

Total 25 patients having colostomy for either Hirchsprung's Disease or Anorectal malformation were selected in such a way that there age, body weight, sex, colostomy site and operative time for colostomy closure were matched well for this comparative study.

They were divided into two groups:
Gr I ( $\mathrm{n}=11$ ) Traditional Feeding patient in Postoperative period and designated as 'Control Group'.

Gr II ( $n=14)$ Early enteral Feeding Patient and designated as 'Study Group'.

As parameter, Postoperative hospital stay and Postoperative complication (vomiting, diarrhoea, wound disruption, lower G.I. bleeding, UTI, URTI and Unspecified fever more than 48 hours) were observed.

\section{Protocol of feeding after colostomy closure:}

\section{Group I:}

a) Patients was kept nothing by mouth until documentation of bowel function, which means a passage of flatus or defecation Usually on $3^{\text {rd }}$ Postoperative day(POD).

b) A nasogastric tube was left in place until content reduce and turns clear.

Group II:

a) Enteral diet was started within 16-24 hours usually in moming of $1^{\text {st }}$ POD. At first clear water was given. Then liquid diet/breast milk was allowed after $3-4$ hours interval. Normal feeding was started on $3^{\text {rd }}$ POD.

b) A nasogastric tube was removed in the morning of first POD.

Unpaired ' $t$ ' test was used to show that statistically Gr-I and Gr-II matched well and that there was no significant difference $(\mathrm{P}>$ 0.05 ) between them with respect to age, body weight, diseases having colostomy, colostomy site and operation time which could influence the study parameters. The same test was also applied for statistical analysis with respect to postoperative hospital stay parameter which shows significant difference between the two groups to fulfill the study purpose. 
Postoperative complications such as (vomiting, diarrhoea, wound disruption, lower G.I. bleeding, UTI, URTI and Unspecified fever more than 48 hours) were compared in between two groups by percentage.

\section{Results:}

Age range (Table-I) of the patients in Group- I and Group- II of our study varied from 10 months to 96 months (mean 34.64 months) and from 14 months to 144 months (mean 59.43 months) respectively. Unpaired ' $\mathrm{t}$ ' test showed no significant difference $\left(\mathrm{P}>0.05^{\mathrm{ns}}\right)$ between the two different groups. Thus two groups were age matched and acceptable for comparative study.

Body weight distribution (Table-I) of the patients in Group- I and Group- II ranged from $6.5 \mathrm{~kg}$ to $19.5 \mathrm{Kg}$ (mean $8 \mathrm{Kg}$ ) and from $8 . \mathrm{kg}$ to $38 \mathrm{Kg}$ (mean $10.50 \mathrm{Kg}$ ) respectively. Unpaired ' $\mathrm{t}$ ' test showed no significant difference $\left(\mathrm{P}>0.05^{\mathrm{ns}}\right.$ ) between the two different groups. Thus two groups were Body weight matched and acceptable for comparative study.

Colostomy site distribution (Table-II) of the patients in Group- I and Group- II had 7 patients $(63.60 \%)$ with transverse colostomy, 4 patients $(36.40 \%)$ with sigmoid colostomy and 8 patients $(57.10 \%)$ with transverse colostomy, 6 patients $(42.90 \%)$ with sigmoid colostomy respectively. Unpaired ' $\mathrm{t}$ ' test showed no significant difference $\left(\mathrm{P}>0.05^{\mathrm{ns}}\right)$ between Gr I and Gr II with respect to colostomy site. Thus two groups were matched with respect to colostomy site and acceptable for comparative study.

Operative time for colostomy closure (TableIII) of the patients in Group- I and Group- II ranged from 40 minutes to 90 minutes (mean 59.09 minutes) and from 25 minutes to 90 (mean 51.43 minutes) respectively. Unpaired ' $\mathrm{t}$ ' test showed no significant difference $(\mathrm{P}>$ $0.05^{\text {ns }}$ ) between the two different groups. Thus two groups with respect to operative time matched and acceptable for comparative study.

Postoperative hospital stay (Table-IV) of the patients in Group-I and Group-II ranged from 6 days to 17 days (mean 8.09 days) and from 3 days to 5 days (mean 4.14 days) respectively. Unpaired " $\mathrm{t}$ " test showed significant (P value $<.002^{* *}$ ) difference in postoperative hospital stay in Group-I and Group-II patients.

Table-V shows that $2(8 \%)$ patients developed Diarrhoea, $1(4 \%)$ patient developed Lower G.I. bleeding, $3(12 \%)$ patients developed URTI in Group- I, whereas in Group- II, only $1(4 \%)$. patients developed URTI in postoperative period.

Table-I: Age and Weight distribution of two groups.

\begin{tabular}{|l|l|l|l|}
\hline Characteristics & $\begin{array}{l}\text { Group-I (n=11) } \\
\text { range(mean) }\end{array}$ & $\begin{array}{l}\text { Group-II(n=14) } \\
\text { range(mean) }\end{array}$ & $\begin{array}{l}\text { P value* } \\
<\mathbf{0 . 0 5}\end{array}$ \\
\hline Age (months) & $10-96(18)$ & $14-144(11.57)$ & $0.11^{\text {Ds }}$ \\
\hline Weight $(\mathrm{kg})$ & $6.5-19.5(8)$ & $8-28(10.5)$ & $0.10^{\text {ns }}$ \\
\hline
\end{tabular}

"= Unpaired "t" test. ns= non significant 
Table-II: Colostomy site distribution in two groups.

\begin{tabular}{|l|c|c|c|}
\hline Colostomy site & Group-I & Group-II & $\begin{array}{c}\text { P value for } \\
\text { Unpaired "t" test }\end{array}$ \\
\hline $\begin{array}{l}\text { Transverse } \\
\text { colon }\end{array}$ & $7(63.60 \%)$ & $8(57.10)$ & $>0.05^{\text {ns }}$ \\
\hline $\begin{array}{l}\text { Sigmoid } \\
\text { colon }\end{array}$ & $4(36.40 \%)$ & $6(42.90 \%)$ & $>0.05^{\text {ns }}$ \\
\hline
\end{tabular}

ns= non significant.

Table-III: Operation time required for colostomy closure in two groups.

\begin{tabular}{|l|c|c|c|}
\hline $\begin{array}{l}\text { Operation } \\
\text { Time(min) }\end{array}$ & $\begin{array}{c}\text { Group-I } \\
(\mathbf{n}=\mathbf{1 1})\end{array}$ & $\begin{array}{c}\text { Group-II } \\
(\mathbf{n}=\mathbf{1 4})\end{array}$ & $\begin{array}{c}\text { P value for } \\
\text { Unpaired " } \mathbf{t} \text { " test }\end{array}$ \\
\hline Range & $(40-90) \mathrm{min}$ & $(25-90) \mathrm{min}$ & \multirow{2}{*}{$\mathrm{P}>0.05^{\mathrm{ns}}$} \\
\hline Mean & $59.09 \mathrm{~min}$ & $51.43 \mathrm{~min}$ & \\
\hline
\end{tabular}

ns= non significant.

Table-IV: Postoperative hospital stays in two groups.

\begin{tabular}{|c|c|c|c|c|c|}
\hline Group & $\begin{array}{l}\text { Number } \\
\text { of patient }\end{array}$ & $\begin{array}{c}\text { Minimum } \\
\text { hospital } \\
\text { stay }\end{array}$ & $\begin{array}{c}\text { Maximum } \\
\text { hospital } \\
\text { stay }\end{array}$ & $\begin{array}{l}\text { Mean } \pm \\
\text { S.D }\end{array}$ & $\begin{array}{c}\text { P value } \\
\text { Unpaired ' } t \text { "' } \\
\text { test }\end{array}$ \\
\hline I (One) & 11 patient & 6 days & 17 days & $8.09 \pm 3.24$ & \multirow[b]{2}{*}{$<.002^{\text {*k }}$ 京 } \\
\hline II (Two) & 14 patient & 3 days & 5 days & $4.14 \pm 0.53$ & \\
\hline
\end{tabular}

$* *=$ Highly significant.

Table-V: Postoperative complication between two groups.

\begin{tabular}{|l|c|c|}
\hline $\begin{array}{l}\text { Postoperative } \\
\text { complication }\end{array}$ & $\begin{array}{c}\text { Group-I } \\
(\mathbf{n}=\mathbf{1 1})\end{array}$ & $\begin{array}{c}\text { Group-II } \\
(\mathbf{n}=\mathbf{1 4})\end{array}$ \\
\hline Vomiting & 0 & 0 \\
\hline Diarrhoea & $2(8 \%)$ & 0 \\
\hline Wound disruption & 0 & 0 \\
\hline Lower GI bleeding & $1(4 \%)$ & 0 \\
\hline UTI & 0 & 0 \\
\hline URTI & $3(12 \%)$ & $1(4 \%)$ \\
\hline Unspecified fever more than 48 hot.rs & 0 & 0 \\
\hline
\end{tabular}

In group-I: Postoperative complication were observed in $6(24 \%)$ patients.

In group-II: Postoperative complication was observed in $1(4 \%)$ patient. 


\section{Discussion:}

Post operative starvation recently has been challenged. Randomized trials in adult lower gastrointestinal tract surgery showed benefit of early enteral feeding in terms of reduction in length of stay and post operative complication.

In this study series nasogastric tube was given to all patients either before operation or during operation. In case of early enteral feeding nasogastric tube omitted on $1^{\text {st }}$ POD in all cases. But in traditional feeding nasogastic tube was omitted from $1^{\text {st }}$ POD to $3^{\text {td }}$ POD.

A study by Tong Zhou et al, nasogastric tubes were removed within 12 to 24 hours after operation in early feeding group. In control group (late feeding group) nasogastric tubes were removed upon report of passes of flatus by patients, usually within 3 to 5 days after surgery ${ }^{3}$.

Elimination of post operative nasogastric tube early decreases post operative fever, pulmonary problems and improves patients comfort by decreasing sore throat and nausea ${ }^{3}$.

Postoperative hospital stay between Group-I and group- II patients of our series showed statistically significant difference ( $P$ value 0.002 ) with lesser hospital stay for Early enteral feeding patients over Traditional feeding patients.

In study by Tsunoda and his colleagues showed the length of hospitalization in early feeding group was significantly shorter than in late feeding group ( 7 days and 10 days $)^{4}$.

The postoperative complications observed in Group-I were Diarrhoea (2 patients), U.R.T.I (3 patients), Lower G.I bleeding ( 1 patient) and in Group-II was U.R.T.I (1 patient). It might be due to nosocomial infection and negative impact of metabolic response to surgery and post operative reactionary haemorrhage (Lower G.I bleeding).

A study in China showed that post operative complications such as fever $(3.73 \%$ vs $9.68 \%$ $\mathrm{p}<0.05)$, Pulmonary infection $(0.62 \%$ vs $4.52 \%, \mathrm{p}<0.05$ ) were much more in control group than in study group ${ }^{3}$.

Another study by Petrelli et all on 104 patients who underwent colorectal surgery including closure of colostomy, oral diet was given in 89 patients on P.O.D 1 or 2.65 patients $(73 \%)$ tolerated early feeding, of 24 patients that did not, 16 had nausea or emesis and 8 required re-admission for post operative complications (such as wound dehiscence, anastomotic leak) univariate analysis revealed that the use of volume expanders contributed to intolerance of early feeding 5 .

In late feeding negative impact of matabolic response to surgery may increase the post operative complications. More staying in hospital post operatively also increase the nosocomial infection (U.R.T.I, Diarrhoea etc).

On the contrary, early enteral feeding can help to improve energy and protein intake. Decrease the negative impact of the metabolic response to injury, stimulate-motor, resorption, synthetic and barrier functions of the small intestine, improve the return of gastrointestinal functions and reduce the duration of post operative ileus and reduce the risk of serious complications. Positive psychological impact of feeding after surgery may have and important role in recovery process.

\section{Conclusion:}

The present study showed that early removing nasogastric tube and early oral feeding in the patients under going colostomy closure is feasible and safe associate with reduced post 
operative complications and discomfort. The study also showed the significant decreased length of post operative hospital stay. It was also parents compliance.

Thus early oral feeding may become a routine feature of management after colostomy closure in pediatric patients.

\section{References:}

1. Surasak S, Sakda P, Kamolnate TS et al. Early enteral feeding after closure of colostomy in paediatric patients. J Pediatr Surg 2003; 38: 1516-19.

2. Lewis SJ, Matthias E, Patrick A S et al. Early enteral feeding versus 'nil by mouth' after gastrointestinal surgery: systemic review and meta analysis of controlled trials. BMJ 2001; 323: 773-76.
3. Tong $\mathrm{Z}$, Xiao-Ting $\mathrm{W}$, Ye-Jiang $\mathrm{Z}$ et al. Early removing gastrointestinal decompression \& early oral feeding improve patients rehabilitation after colorectostomy. World J Gastroenterol 2006; 12: 2459-63.

4. AkiraT, Mattew S, Molitt T et al. Early oral feeding should be resumed following the resolution of gastric ileus. J of HepatoGastroenterol 2005; 52: 775-79.

5. Nicholas JP, Charles C, Deborah D et al. Early postoperative oral feeding after colectomy, An analysis of factors that may predict failure. Annals of surg oncology 2001; 8: 796-800. 